\title{
Philometrid nematodes (Philometridae) from marine fishes off the northern coast of Australia, including three new species
}

\author{
František Moravec $^{1}$ and Ben K. Diggles ${ }^{2}$ \\ ${ }^{1}$ Institute of Parasitology, Biology Centre of the Academy of Sciences of the Czech Republic, České Budějovice, Czech Republic; \\ ${ }^{2}$ DigsFish Services Pty Ltd., Banksia Beach, Australia
}

\begin{abstract}
Based on light and scanning electron microscopical studies, the following nine species of Philometridae (Nematoda: Dracunculoidea) are described from female worms parasitizing marine perciform fishes belonging to six families off the northern coast Australia (near Darwin): Philometra australiensis sp. n. from the swimbladder of the king threadfin Polydactylus macrochir (Günther) (Polynemidae); P. epinepheli Dewi et Palm, 2013 from the operculum of the orange-spotted grouper Epinephelus coioides (Hamilton) (Serranidae); Philometra johnii Moravec et Ali, 2013 from the gonad of the croaker Johnius sp. (Sciaenidae); P. macrochiri sp. n. from the sensory fin of P. macrochir; P. zabidii sp. n. from the ovary of the ninespine batfish Zabidius novemaculeatus (McCulloch) (Ephippidae); Philometra sp. 1 and Philometra sp. 2 from the ovary of the Spanish flag snapper Lutjanus carponotatus (Richardson) (Lutjanidae) and the silver grunt Pomadasys argenteus (Forsskål) (Haemulidae), respectively; Philometroides eleutheronemae Moravec et Manoharan, 2013 from the ovary of the fourfinger threadfin Eleutheronema tetradactylum (Shaw) (Polynemidae); and Spirophilometra endangae Dewi et Palm, 2013 from the pectoral fins of E. coioides. The new species $P$. australiensis is characterized mainly by the structure of the cephalic end, 14 minute cephalic papillae, absence of caudal projections and body length of gravid female $(67 \mathrm{~mm}), P$. macrochiri by the presence of a conspicuously large anterior oesophageal bulb, 14 very small cephalic papillae and the truncated posterior end of body without any caudal projections, whereas $P$. zabidii is characterized by the presence of distinct caudal projections, the number (14) and larger size and arrangement of cephalic papillae, a poorly developed anterior oesophageal inflation, the body length $(114 \mathrm{~mm})$ and the host family (Ephippidae). All above-mentioned species were recorded from Australian waters for the first time.
\end{abstract}

Keywords: taxonomy, diversity, endoparasites, fish host, fish parasites, Nematoda, Philometra, Philometroides, Spirophilometra

The nematode family Philometridae Baylis et Daubney, 1926 contains a large number of species parasitic in the abdominal cavity and various body tissues of freshwater, brackish-water and marine fishes; some of them are pathogenic parasites occurring frequently in commercially important wild or cultured fish hosts (Ivashkin et al. 1971, Moravec 2006, Moravec and de Buron 2013). Due to some morphological and biological peculiarities, most of them are known only by their large-sized females.

The knowledge of the fauna of these nematodes parasitizing fishes in Australian waters remains fragmentary. To date, the only known nominal philometrid species in this region are two representatives of Philometroides Yamaguti, 1935, P. plectroplites (Johnston et Mawson, 1940) and P. similis Moravec, 2006, in freshwater fishes Macquaria ambigua (Richardson) (Percichthyidae) and Anguilla reinhardtii Steindachner (Anguillidae), respectively (Johnston and Mawson 1940, Moravec 2006), and four species of Philometra Costa, 1845 in marine and brackish-water fishes: P. kohnae Moravec et Rohde, 1992 and P. lomi Moravec et Rohde, 1992 in Tylosurus gavialoides (Castelnau) (Belonidae), P. percalates Johnston et Mawson, 1940 in Macquaria colonorum (Günther) (Percichthyidae) and P. sydneyi Rasheed, 1963 in an unidentified fish (Johnston and Mawson 1940, Rasheed 1963, Moravec and Rohde 1992).

In addition, the gonad-infecting species Philometra lateolabracis (Yamaguti, 1935) was reported from the marine fish Glaucosoma hebraicum Richardson (Glaucosomatidae) off Western Australia by Hesp et al. (2002). However, according to Moravec (2008) and Quiazon et al. (2008), this identification is doubtful and the nematodes should be designated as Philometra sp. An additional ten nominal species of Philometra parasitizing marine fishes were reported from off New Caledonia, South Pacific (Moravec and Justine 2008, 2009, 2011, Moravec and de Buron 2013), which may also occur in Australian waters.

During parasitological investigations on some marine fishes off the northern Australian coast in the region of 
Darwin Harbour, carried out from August 2012 to March 2013, philometrid nematodes (only females) were found in eight species of perciform fishes belonging to Ephippidae (1), Haemulidae (1), Lutjanidae (2), Polynemidae (2), Sciaenidae (1) and Serranidae (1). Their closer examination revealed that they are representatives of three philometrid genera, Philometra, Philometroides and Spirophilometra Parukhin, 1971; these nematodes are described herein.

\section{MATERIALS AND METHODS}

Fish were collected using hook and line and gill nets from Darwin Harbour $\left(12^{\circ} 29^{\prime} \mathrm{S}, 130^{\circ} 49^{\prime} \mathrm{E}\right)$, Bynoe Harbour $\left(12^{\circ} 41^{\prime} \mathrm{S}\right.$, $\left.130^{\circ} 34^{\prime} \mathrm{E}\right)$, and near the mouth of the Adelaide River $\left(12^{\circ} 13^{\prime} \mathrm{S}\right.$, $131^{\circ} 13^{\prime} \mathrm{E}$ ) between August 2012 and March 2013. Once a fish was caught it was visually examined for any signs of external abnormality such as lesions, discolourations or deformities. All fish showing signs of abnormality and a random subsample of apparently normal individuals were returned to the laboratory for further examination. Fish taken for parasitological examination were euthanised by brain destruction, placed in a sealed plastic bag and stored on ice for transportation back to the laboratory. Each fish was measured (total length), weighted, and examined externally for lesions and other gross signs of disease.

The paired fins (pectoral and pelvic), operculum and gill arches on the left side of each fish were excised and examined under a dissecting microscope for parasites and lesions. The fish was then dissected and the internal organs were examined for parasites and lesions. Nematodes obtained were washed in physiological saline and then fixed and preserved in $70 \%$ ethanol. For light microscopy examination, the nematodes were cleared with glycerine. Drawings were made with the aid of a Zeiss drawing attachment. Specimens used for scanning electron microscopy (SEM) were postfixed in $1 \%$ osmium tetroxide (in phosphate buffer), dehydrated through a graded acetone series, criticalpoint-dried and sputter-coated with gold; they were examined using a JEOL JSM-7401F scanning electron microscope at an accelerating voltage of $4 \mathrm{kV}$ (GB low mode). All measurements are in micrometres unless otherwise indicated. The fish nomenclature adopted follows FishBase (Froese and Pauly 2013).

\section{RESULTS}

\section{Philometra australiensis sp. $\mathrm{n}$.}

Figs. 1, 2

Female (one gravid specimen, holotype): Body of fixed specimen brownish, filiform, with smooth cuticle and rounded ends; body length $67 \mathrm{~mm}$, maximum width $1.37 \mathrm{~mm}$, its maximum width/body length ratio $1: 49$; posterior part of body somewhat narrower than anterior part. Width of cephalic end 408, of caudal end 476. Cephalic end rounded, with four somewhat elevated longitudinal submedian mounds whose proximal ends surround central, roughly hexagonal plate with oral aperture and cephalic papillae (Figs. 1D, 2B-D); papillae indistinct when viewed laterally (Fig. 1A,B). Oral aperture rather small, almost circular, surrounded by four pairs of very small submedian cephalic papillae of external circle and six minute single papillae (two lateral and four submedian) of internal circle (Figs. 1F). Amphids indistinct.

Oesophagus including anterior bulbous inflation $1.20 \mathrm{~mm}$ long, representing $2 \%$ of body length, maximum width of its posterior portion including oesophageal gland 150; anterior bulb well developed, markedly broad, 95 long and 150 wide, relatively small in relation to anterior body end (Fig. 1A,B). Oesophageal gland well developed, opening into oesophagus just posterior to nerve ring; large cell nucleus at about middle of gland, 694 from anterior extremity. Nerve ring 218 from anterior end of body. Small ventriculus 41 long and 95 wide present (Fig. 1A). Oesophagus opening into intestine through distinct valve. Intestine brown, relatively narrow at anterior end, ending blindly; intestinal ligament not visible.

Vulva and anus absent. Ovaries narrow, reflected, situated near body ends. Uterus occupying most space of body, filled with numerous larvae and eggs, extending anteriorly to nerve ring and posteriorly almost to posterior extremity (Fig. 1A,E). Larvae from uterus 438-480 long, maximum width 15-16; length of oesophagus 135-150, representing $31 \%$ of body length; sharply pointed tail 93-102 long, representing $21-23 \%$ of body length (Fig. 1C). Posterior end of adult rounded, without any caudal projections (Fig. 1E).

Male: Unknown.

Type host: King threadfin, Polydactylus macrochir (Günther) (Polynemidae: Perciformes).

Site of infection: Swimbladder.

Type locality: Adelaide River, near Darwin, Australia (collected 28 November 2012 by K.S. Hutson).

Prevalence and intensity: 7\% (1 fish infected/15 fish examined from Adelaide River; 1 nematode). Not present in 16 fish from Bynoe Harbour or 4 fish from Darwin Harbour. Overall prevalence $=1 / 35$ fish $(3 \%) ; 1$ specimen.

Deposition of type specimen: Holotype (SEM stub) in the Helminthological Collection of the Institute of Parasitology, Biology Centre of the Academy of Sciences of the Czech Republic, České Budějovice (Cat. No. N - 1016).

Etymology: The specific name of this nematode relates to the country of its origin.

Remarks. The general morphology of this specimen corresponds to the diagnosis of Philometra (see Rasheed 1963, Moravec 2006). Species of this genus, as well as those of other philometrid genera, exhibit a relatively high degree of host specificity and, moreover, individual species are characterized by their location in the host, particularly that of gravid females (Ivashkin et al. 1971, Moravec 2006, Quiazon et al. 2008).

To date, the following five nominal species of philometrids have been reported from fishes of the family Polynemidae: Philometra lateolabracis (Yamaguti, 1935) from the ovary of Eleutheronema tetradactylum (Shaw) in the Indian Ocean; P. polynemii Rasheed, 1963 from the abdominal cavity of E. tetradactylum in the Indian Ocean off Pakistan and the ovary of Polydactylus sextar- 




Fig. 1. Philometra australiensis sp. $\mathrm{n}$. from swimbladder of Polydactylus macrochir, gravid female. A - anterior end of body, lateral view; B - shape of oesophageal bulb; C - larva from uterus; D - anterior end of body, apical view; $\mathbf{E}$ - posterior end, lateral view; $\mathbf{F}$ - cental region of anterior end of body, apical view.

ius (Bloch et Schneider) in the Monar Bay; P. beninensis Obiekezie, 1986 mainly from fins of Polydactylus quadrifilis (Cuvier) in the Eastern Central Atlantic off Nigeria; $P$. rajani from the ovary of $E$. tetradactylum probably off the coast of India; and Philometroides eleutheronemae Moravec et Manoharan, 2013 also from the coast of India (see Moravec 2006, Moravec and Manoharan 2013).

Of them, however, $P$. lateolabracis was evidently misidentified and should be considered Philometra sp. (see Moravec 2008, Quiazon et al. 2008) and P. rajani, taken for a synonym of $P$. lateolabracis by Soota (1983), was designated a species inquirenda by Moravec and Manoharan (2013). In contrast to $P$. australiensis, gravid females of $P$. lateolabracis are much longer (132-230 mm), their anterior oesophageal inflation is moderately developed and structure of their cephalic end is different (the hexagonal cephalic plate and submedian mounds are absent) (Moravec 2006); moreover, both species differ in their location in the host (gonads $v s$ swimbladder).

The new species can be easily distinguished from $P$. beninensis by the absence of eight conspicuously large fleshy cephalic papillae, from $P$. polynemii by the absence of large caudal projections and from Philometroides eleutheronemae by the absence of cuticular bosses and the structure of the oesophagus and cephalic end. The new species can be differentiated from all other species of Philometra by the combination of morphological features, mainly by the characteristic structure of the cephalic end. 

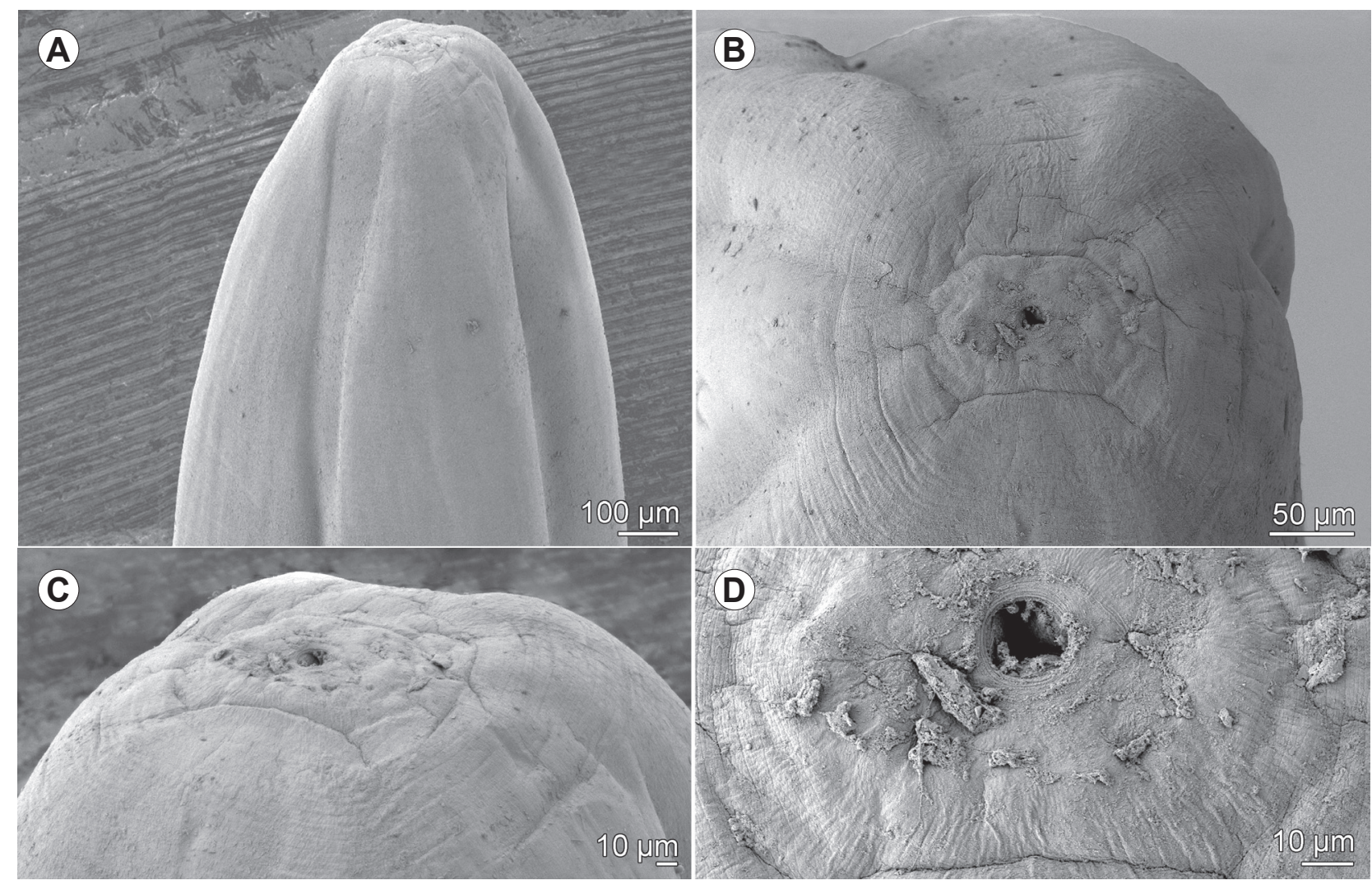

Fig. 2. Philometra australiensis sp. n. from swimbladder of Polydactylus macrochir, scanning electron micrographs of gravid female. A - anterior end of body, sublateral view; B, C - cephalic end, apical and sublateral views; $\mathbf{D}$ - central cephalic region bearing indistinct papillae, apical view.

The authors are aware of the fact that $P$. australiensis is being described from a single specimen, a procedure that cannot be generally recommended. However, it this case, the new species seems to be well established, and, therefore, they consider it more reasonable and useful to give it a specific name than to report it as Philometra sp.

\section{Philometra epinepheli Dewi et Palm, 2013 Figs. 3, 4}

Female (four gravid specimens): Body of fixed specimens yellowish, 22.5-33.6 mm long and 625-734 in maximum width, markedly narrowed towards anterior and posterior extremities; maximum width/length ratio of body $1: 33-46$; anterior part of body somewhat wider than posterior part; width of cephalic end 122-150, that of caudal end 54-68. Cuticle finely transversely striated (Fig. 4A,B). Cephalic end rounded, cephalic papillae small, indistinct in lateral view (Figs. 3A,B, 4A,B). Oral aperture circular, large, surrounded by 14 cephalic papillae arranged in two circles. External circle formed by four pairs of submedian papillae; papillae of each pair relatively far from each other, consisting of one circular and one more elongate papilla. Internal circle formed by four submedian single papillae and one pair of minute single lateral papillae (Fig. 3C). Lateral amphids indistinct.
Oesophagus muscular, inflated at anterior end to form distinct bulb, $1.09-1.22 \mathrm{~mm}$ long, comprising $4-5 \%$ of body length (Fig. 3A). Oesophageal bulb 99-105 long and 117-129 wide, with spacious lumen. Longer, posterior part of oesophagus somewhat expanded, maximum width of oesophagus including oesophageal gland 95-109. Latter large, extending from posterior end of oesophagus to level of nerve ring; its nucleus at 816-857 from anterior end of body. Ventriculus small, 27 long and 54-68 wide, opening into intestine through valve (Fig. 3A). Nerve ring encircling oesophagus 218-258 from anterior extremity (Fig. 3A). Intestine brown, straight, ending blindly; anterior end of intestine relatively narrow; posterior end of intestine atrophied, forming markedly long ligament measuring $1.12-5.51 \mathrm{~mm}$, attached ventrally to body wall close to posterior extremity (Fig. 3D).

Ovaries short, reflexed, situated near anterior and posterior body ends (Fig. 3A,D). Uterus occupying major part of body, filled with numerous larvae and eggs. Larvae $(\mathrm{n}=5)$ 375-441 long, maximum width 15-18; oesophagus $75-108$ long (18-25\% of body length), length of tail 81-96 (19-22\%). Posterior end of body conical, with rouded tip bearing two distinct lateral papilla-like caudal projections (Fig. 3F,G).

Male: Unknown. 


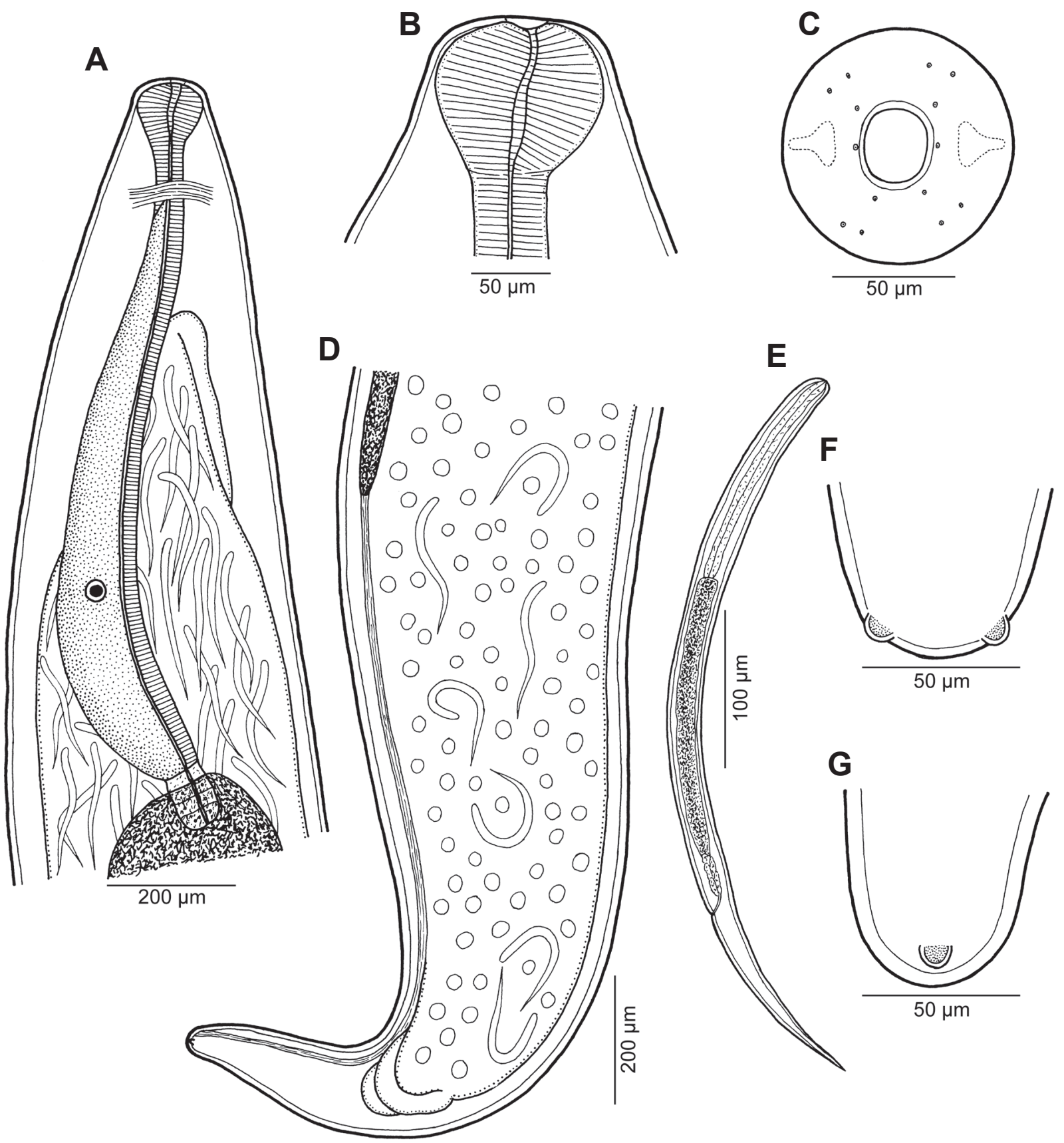

Fig. 3. Philometra epinepheli Dewi et Palm, 2013 from operculum of Epinephelus coioides, gravid female. A - anterior end of body, lateral view; B - oesophageal bulbous inflation; $\mathbf{C}$ - cephalic end, apical view; D - posterior end of body, lateral view; $\mathbf{E}$ - larva from uterus, lateral view; $\mathbf{F}, \mathbf{G}$ - tail tip, dorsoventral and lateral views, respectively.

Host: Orange-spotted grouper, Epinephelus coioides (Hamilton) (Serranidae, Perciformes).

Site of infection: Opercula (inner side).

Localities: Bynoe Harbour and Darwin Harbour, near Darwin, Australia (collected December 2012 by B.K. Diggles).

Prevalence and intensity: 14\% (3 fish infected/21 fish examined from Bynoe Harbour; mean intensity 2.3 nematodes per fish, range 2-3). Also present in 1 fish from Darwin Harbour (1 fish infected/38 fish examined; 1 nematode). Not found in 15 fish from Adelaide River. Overall prevalence = 4/74 fish
$(5 \%)$; mean intensity $=2$, range $1-3$.

Deposition of voucher specimens: Helminthological Collection of the Institute of Parasitology, Biology Centre, Academy of Sciences of the Czech Republic, in České Budějovice (Cat. No. N-1019).

Remarks. The morphology of specimens of the present material is, more or less, in agreement with the description of P. epinepheli Dewi et Palm, 2013, a philometrid recently described from the opercula of Epinephelus coioides in the South Bali Sea, Indonesia (Dewi and Palm 

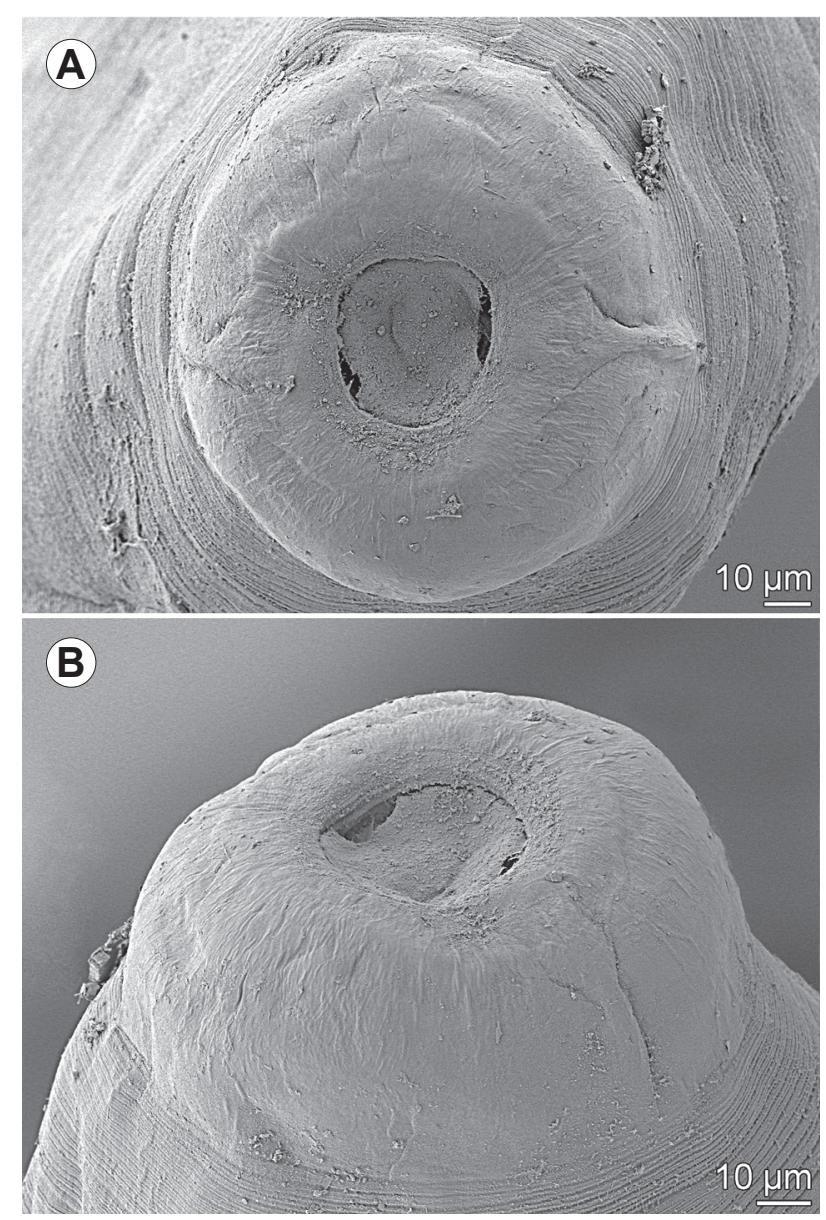

Fig. 4. Philometra epinepheli Dewi et Palm, 2013 from operculum of Epinephelus coioides, scanning electron micrographs of gravid female. A, B - cephalic end, apical and sublateral views.

2013). Since the host species and the site of infection in the host are identical, it supports further that the present specimens belong to this species.

Dewi and Palm (2013) reported the body length of $P$. epinepheli gravid females to be $7.8-17.8 \mathrm{~mm}$, whereas females of the present material were distinctly longer (22.48-33.55 mm). Moreover, the oesophageal gland of this species was reported in the original description as poorly developed, whereas it is well developed, rather large in the present specimens.

However, these differences are probably within the intraspecific biometrical variability of $P$. epinepheli or may be due to some inaccurate observations. Characteristic features of this species, i.e. a conical caudal end of the body and an unusually long intestinal ligament, were not mentioned by Dewi and Palm (2013). The present finding is the first record of $P$. epinepheli from Australian waters.

Philometra johnii Moravec et Ali, $2013 \quad$ Figs. 5, 6

Female (one gravid specimen): Body of fixed specimens ochre-coloured, with rounded ends. Posterior part of body narrower than anterior part; maximum width in region posterior to oesophagus. Cuticle smooth. Body length $186 \mathrm{~mm}$, maximum width 884, maximum width/ body length ratio $1: 210$. Width of cephalic end 231 . Oral aperture almost circular, surrounded by four pairs of small submedian cephalic papillae of external circle and six small single papillae (two lateral and four submedian) of internal circle (Figs. 5C, 6A,B). Amphids indistinct. Oesophagus including anterior bulbous inflation $1.16 \mathrm{~mm}$ long, comprising $0.6 \%$ of body length; anterior inflation 150 long and 163 wide; maximum width of oesophagus including gland 177.

Oesophageal gland opening into oesophagus just posterior to nerve ring, with large cell nucleus in middle (Fig. 5A). Nerve ring and oesophageal nucleus 286 and 775 , respectively, from anterior extremity. Small ventriculus 27 long and 82 wide. Oesophagus opening into intestine through distinct valve (Fig. 5A). Intestine narrow at anterior end (Fig. 5A); its posterior end attached by ligament ventrally to body wall near caudal end.

Vulva and anus atrophied. Ovaries long, reflected, situated near body ends (Fig. 5A,E); posterior ovary forming numerous coils (Fig. 5E). Uterus occupying most space of body, filled with numerous larvae with sharply pointed tail (Figs. 5D, 6D); larvae $(n=5)$ 438-495 long and 18-21 wide; length of oesophagus $96-150$, of tail 114-138, representing $19-31 \%$ and $23-29 \%$, respectively, of entire body length of larva. Posterior end of female rounded (Fig. 6C), 177 wide, with two small, hardly visible lateral papilla-like caudal projections (Fig. 5F).

Host: Croaker, Johnius sp. (Sciaenidae, Perciformes).

Site of infection: Ovary.

Locality: Adelaide River, near Darwin, Australia (collected 17 October 2012 by K.S. Hutson).

Prevalence and intensity: 7\% (2 fish infected/30 fish examined from Adelaide River; mean intensity 3 nematodes per fish, range 2-4). Not present in 5 fish from Darwin Harbour or in 1 fish from Bynoe Harbour. Overall prevalence $=2 / 36$ fish $(6 \%)$.

Deposition of voucher specimen: Helminthological Collection of the Institute of Parasitology, Biology Centre of the Academy of Sciences of the Czech Republic, České Budějovice (Cat. No. N - 1005).

Remarks. The only available specimen of the present material is both morphologically and biometrically very similar to Philometra johnii Moravec et Ali, 2013, recently described from the ovary of Johnius dussumieri $(\mathrm{Cu}-$ vier) in the Persian Gulf off Iraq (Moravec and Ali 2013). Since also the location in the host is identical and both forms occur in congeneric fish hosts, the present specimen is considered to belong to this species. This identification can be confirmed when conspecific males from Australian waters are at disposal.

Philometra macrochiri sp. n.

Figs. 7-9

Female (two gravid specimens; measurements of holotype, those of paratype in parentheses): Body of nonencapsulated specimen (holotype) ochre-coloured, cylin- 
A
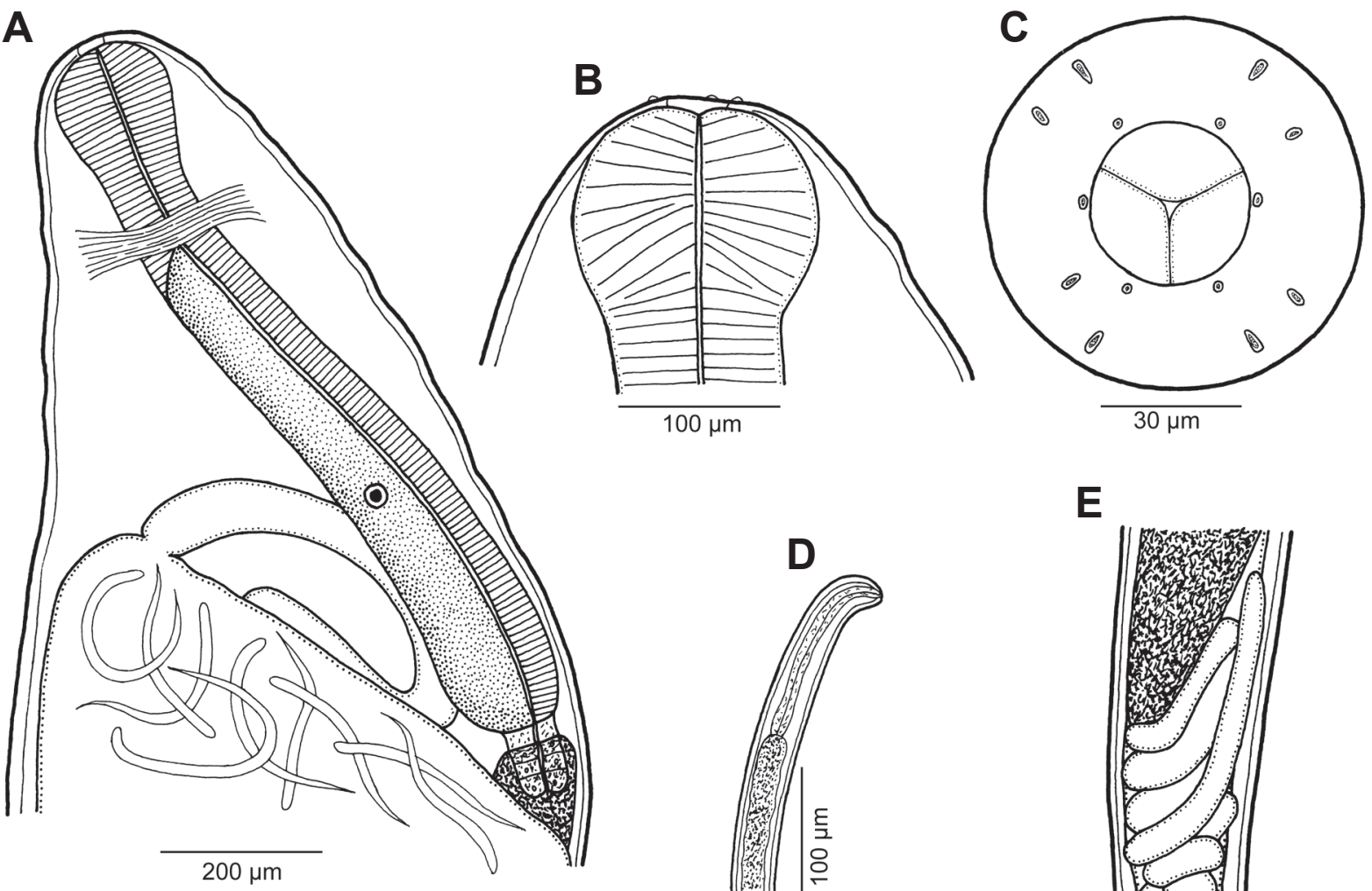

$\mathbf{F}$



E
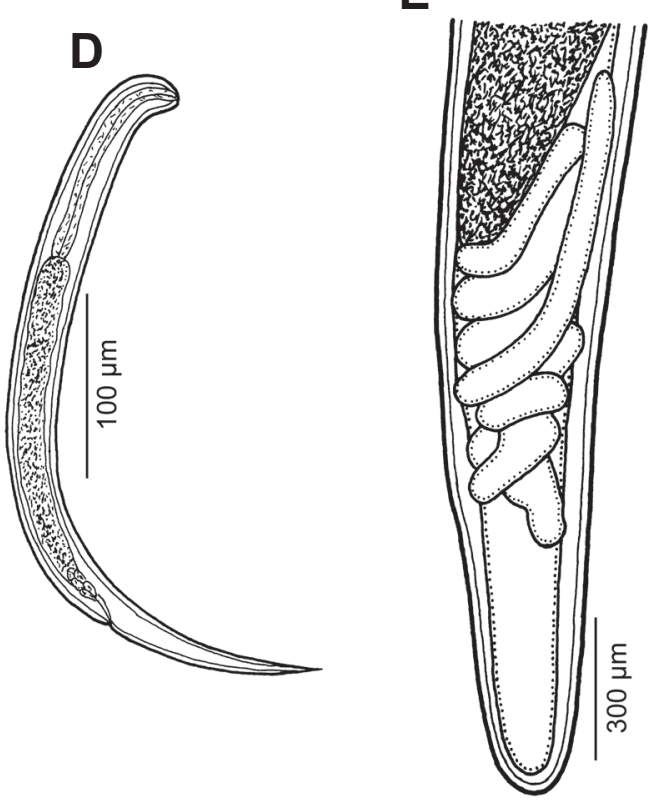

Fig. 5. Philometra johnii Moravec et Ali, 2013 from ovary of Johnius sp., gravid female. A - anterior end of body, lateral view; $\mathbf{B}$ - anterior oesophageal inflation; $\mathbf{C}$ - cephalic end, apical view; $\mathbf{D}$ - larva from uterus, lateral view; $\mathbf{E}$ - posterior end, lateral view; F - tail tip, dorsoventral view.

drical, with truncated ends (body of paratype plump, very thick, dark, non-transparent). Cuticle of holotype smooth (cuticle of paratype densely transversely wrinkled, some wrinkles forming somewhat elevated short transverse structures (Fig 8F). Body length 37.5 (about 13) mm, maximum width 966 (about $3 \mathrm{~mm}$ ), maximum width/ body length ratio $1: 39$ (about $1: 4$ ). Width of cephalic end 449 (408). Cephalic papillae very small, indistinct when viewed laterally (Fig. 7A,D,E). Oral aperture almost circular (Figs. 7C, 8A-C), surrounded by four pairs of minute, hardly visible submedian cephalic papillae of external circle and six very small single papillae (two lateral and four submedian) of internal circle (Fig. 7C). Amphids indistinct. Cephalic region surrounding oral aperture and bearing papillae separated from rest of body by distinct groove (Fig. 8A-C).

Oesophagus including anterior bulbous inflation 966 (-) long, comprising $2.6(-) \%$ of body length; anterior bulb markedly large, well separated from rest of oesophagus, 231 (177) long and 286 (258) wide; maximum width of posterior cylindrical portion of oesophagus including gland $122(-)$. Oesophageal gland opening into oesophagus just posterior to nerve ring, with large cell nucleus in middle (Fig. 7A). Nerve ring and oesophageal nucleus 299 (231) and $558(-)$, respectively, from anterior extremity. Small ventriculus 27 (-) long and 82 (-) wide. Oesophagus opening into intestine through distinct valve (Fig. 7A). Intestine brown, narrow at anterior end (Fig. 7A); its posterior end forming coils (markedly broad in paratype); end of intestine attached by short ligament ventrally to body wall near caudal end (Fig. 7G-H); ligament 394 (-) long.

Vulva and anus atrophied. Ovaries tubular, situated near body ends (Fig. 7A,F). Uterus occupying most space of body, extending anteriorly to level of nerve ring and posteriorly almost to posterior extremity of body (Fig. 7A,F,G), filled with numerous larvae with sharp- 

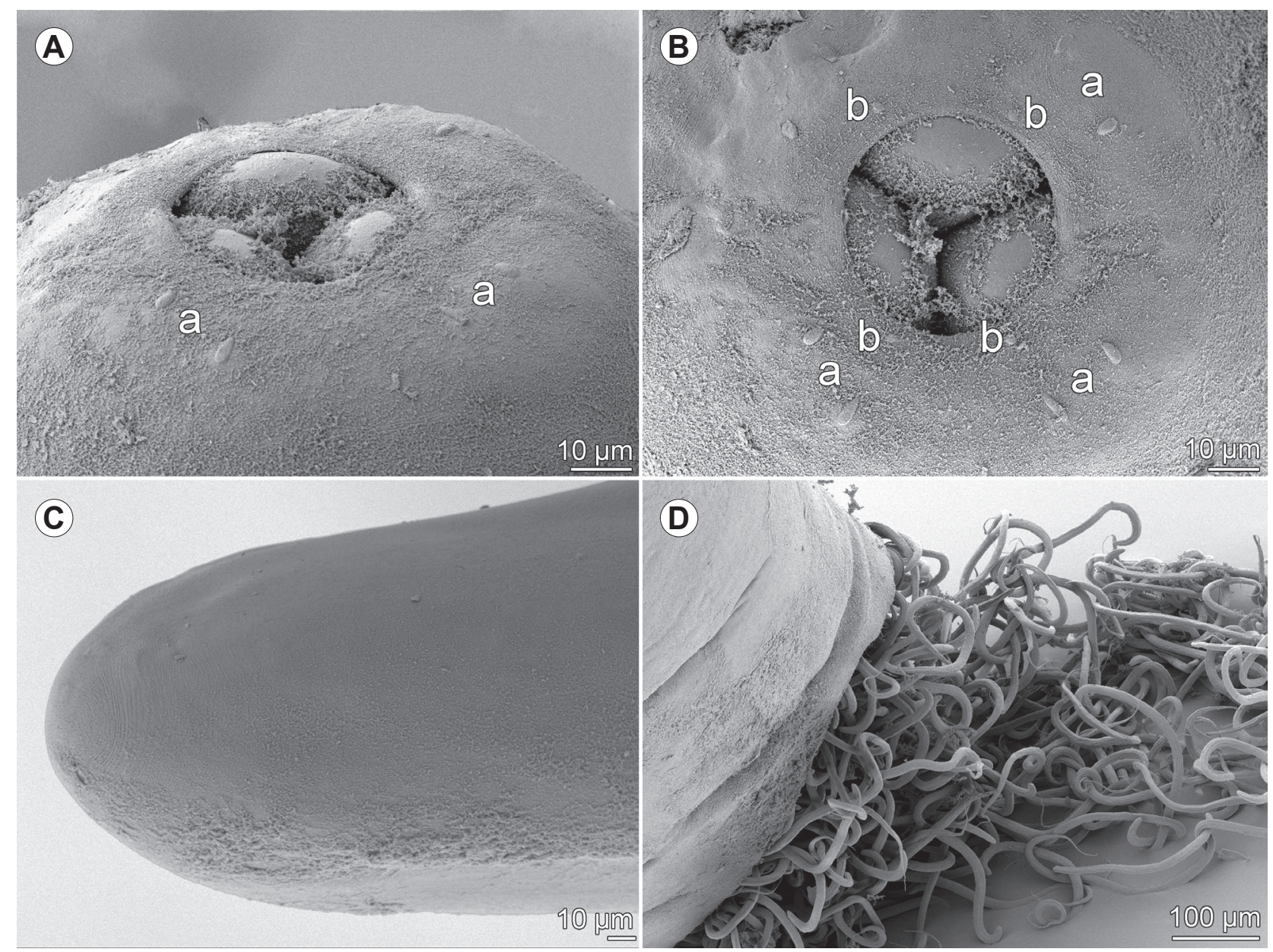

Fig. 6. Philometra johnii Moravec et Ali, 2013 from ovary of Johnius sp., scanning electron micrographs of gravid female. A, B - cephalic end, ventral and apical views; $\mathbf{C}$ - posterior end of body, lateral view; D - larvae escaping from damaged body. Abbreviations: $\mathrm{a}$ - submedian pair of cephalic papillae of external circle; $b$ - submedian cephalic papilla of internal circle.

ly pointed tail (Figs. 7B, 8E). Larvae $(\mathrm{n}=5) 390-411$ (366-396) long and 15 (15-18) wide; length of oesophagus $90-105$ (84-105), of tail 87-90 (87-102), representing 23-26 (22-29)\% and 21-23 (23-27)\%, respectively, of entire body length of larva. Posterior end of female truncated, 680 (1156) wide, without any caudal projections (Fig. 7F-H).

Male: Unknown.

Type host: King threadfin, Polydactylus macrochir (Günther) (Polynemidae, Perciformes).

Site of infection: Sensory fin (body of holotype located parallel with fin ray, non-encapsulated; body of paratype inside oval capsule attached to fin ray).

Type locality: Darwin Harbour, near Darwin, Australia (collected 5 August 2012 by B.K. Diggles).

Prevalence and intensity: 50\% ( 2 fish infected $/ 4$ fish examined from Darwin Harbour; mean intensity 1.5 nematodes per fish, range 1-2). Not present in 16 fish from Bynoe Harbour or 15 fish from Adelaide River. Overall prevalence $=2 / 35$ fish $(6 \%)$.

Deposition of type specimens: Holotype and paratype (both SEM stubs) in the Helminthological Collection of the Institute of Parasitology, Biology Centre of the Academy of Sciences of the Czech Republic, České Budějovice (Cat. No. $\mathrm{N}-1017)$.

Etymology: The specific name of this nematode relates to the genitive form of the specific name of the host.

Remarks. Although both available specimens from P. macrochir somewhat differ in body shape and size and in the appearance of the surface of the cuticle, we consider them conspecific. These differences are probably associated with the fact that the smaller specimen (paratype) was encapsulated by host tissue, so that the limited space inside the capsule did not permit the worm to grow as much as the non-encapsulated specimen (holotype). It is possible that from the same reason the surface of the cuticle of the paratype was transversely wrinkled, forming slightly elevated small transverse structures (Fig. 8F) in some regions of the body. The specimens are identical in all other morphological features.

The new species resembles only three other congeners parasitizing marine fishes in having a conspicuously large 


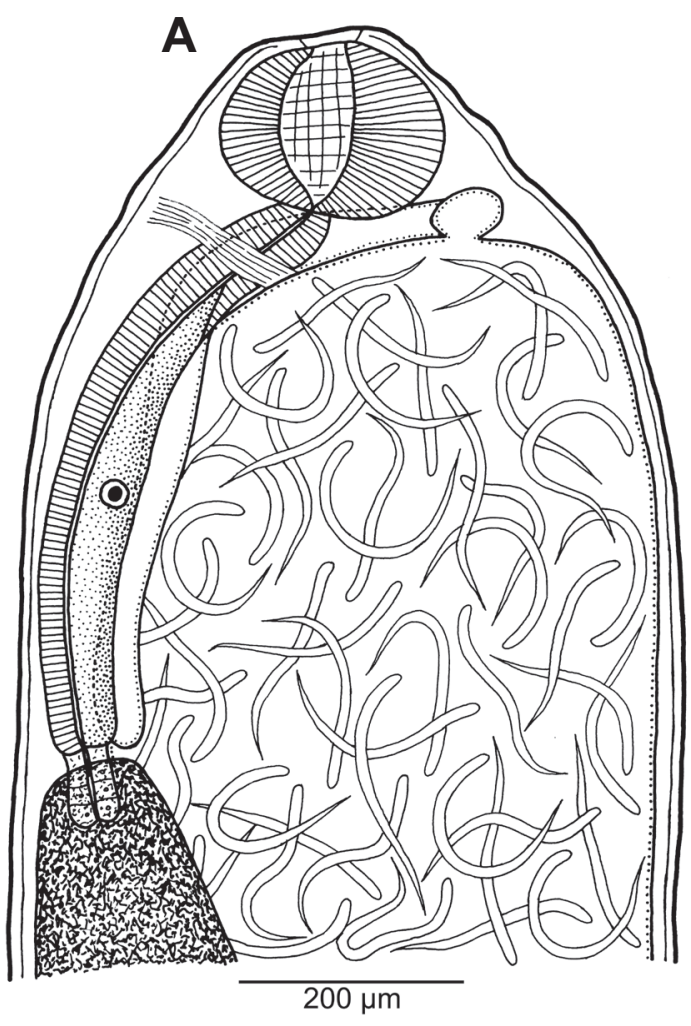

B

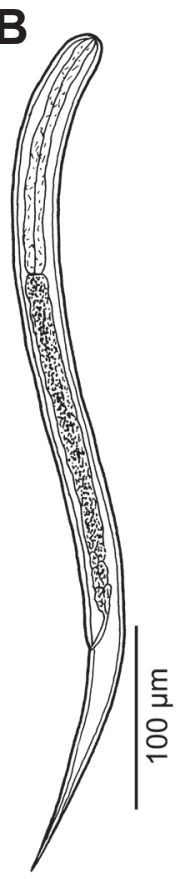

틍


우

D

$\mathbf{F}$

E
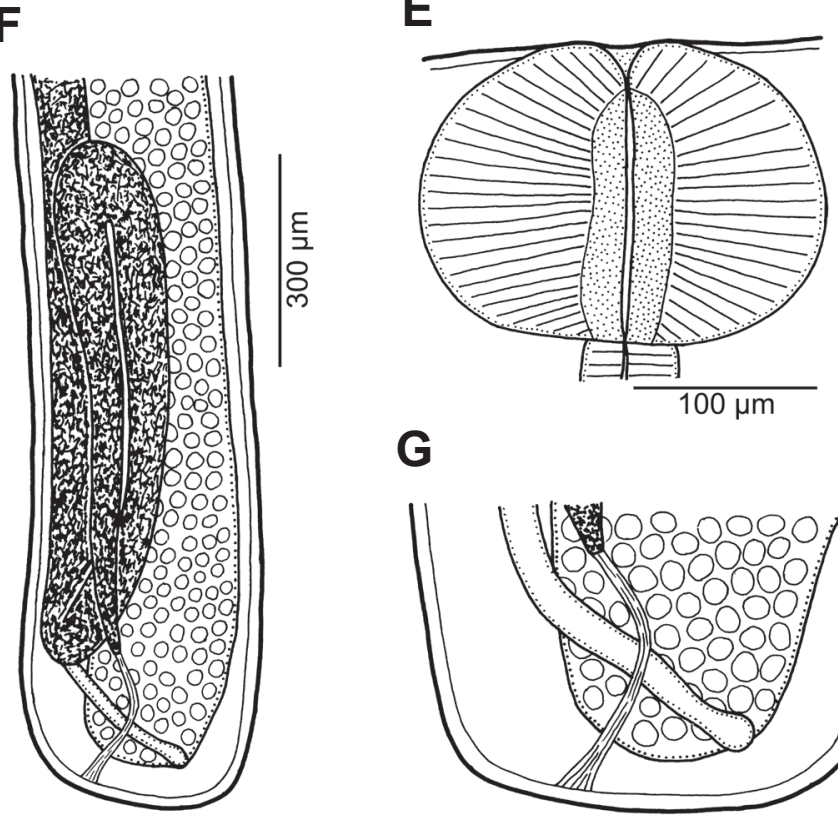

G



H

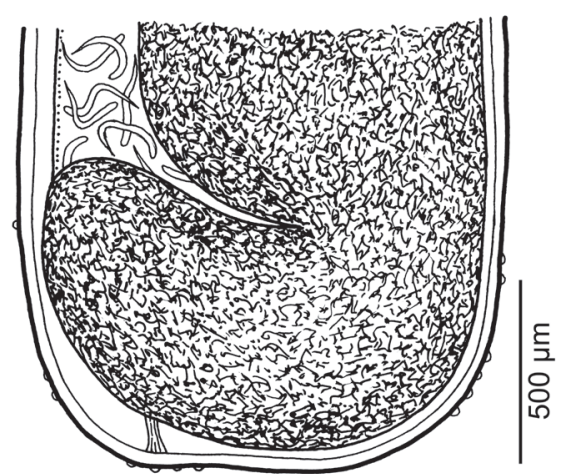

Fig. 7. Philometra macrochiri sp. n. from sensory fin of Polydactylus macrochir, gravid female. A - anterior end, lateral view; $\mathbf{B}$ - larva from uterus, lateral view; $\mathbf{C}$ - cephalic end, apical view; $\mathbf{D}, \mathbf{E}$ - anterior oesophageal bulb, lateral view (different specimens); $\mathbf{F}$ - posterior end, lateral view; $\mathbf{G}$ - caudal end, lateral view; $\mathbf{H}$ - caudal end of another specimen with contracted cuticle, lateral view.

anterior oesophageal bulb distinctly separated by a constriction from the remaining portion of the oesophagus: Philometra ivaschkini Parukhin, 1976 from the stomach wall of Trichiurus lepturus Linnaeus (Trichiuridae) in the Gulf of Aden and the Indian Ocean off the south-eastern
African coast (Parukhin 1976); P. kohnae Moravec et Rohde, 1992 from capsules in subcutaneous pouches of Tylosurus gavialoides (Belonidae) in the Pacific off the eastern Australian coast (Moravec and Rohde 1992); and P. strongylurae Moravec et Ali, 2005 from the subcutane- 

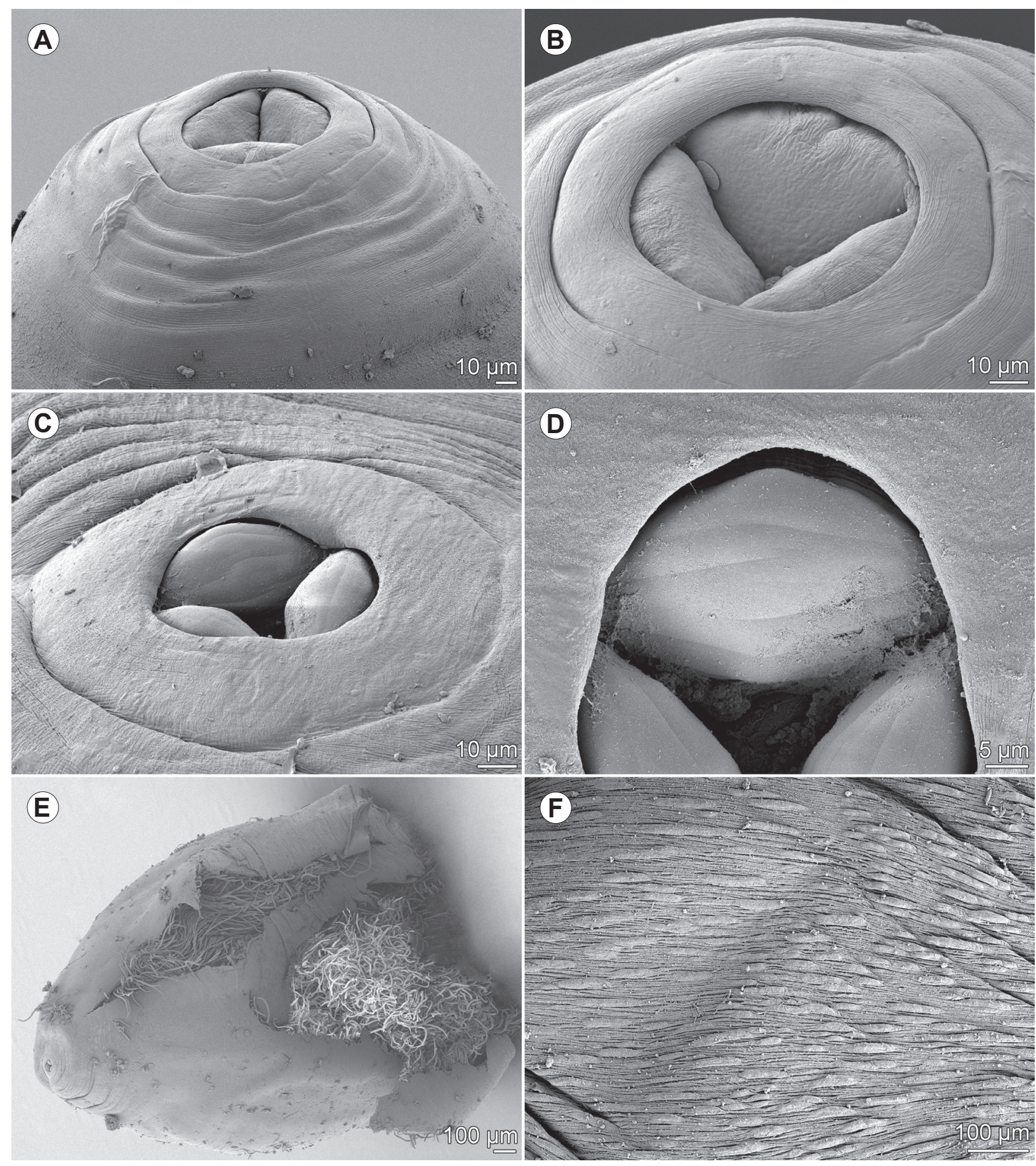

Fig. 8. Philometra macrochiri sp. n. from sensory fin of Polydactylus macrochir, scanning electron micrographs of gravid female. A-C - cephalic end, subdorsal, apical and subventral views, respectively; D - detail of oral aperture, apical view; $\mathbf{E}$ - larvae escaping from broken body; $\mathbf{F}$ - cuticle of paratype with distinct small transverse elevated structures.

ous tissue and gills of Strongylura leiura (Bleeker) and S. strongylura (van Hasselt) (Belonidae) in the Persian Gulf (Moravec and Ali 2005).

Whereas both $P$. kohnae and $P$. strongylurae differ from the new species mainly in possessing eight conspicuously large cephalic papillae ( $v s 16$ very small papillae), the inadequately described $P$. ivaschkini can be differenti- ated by the alleged presence of three papilla-like cephalic protrusions and a strongly tapering, rounded caudal end.

By the general body appearance and the structure of the oesophagus with a markedly large anterior bulb, the new species also resembles Clavinema mariae (Layman, 1930), a parasite from the fins and subcutaneous tissues of a variety of pleurinectiform, scorpaeniform, gobiesoci- 


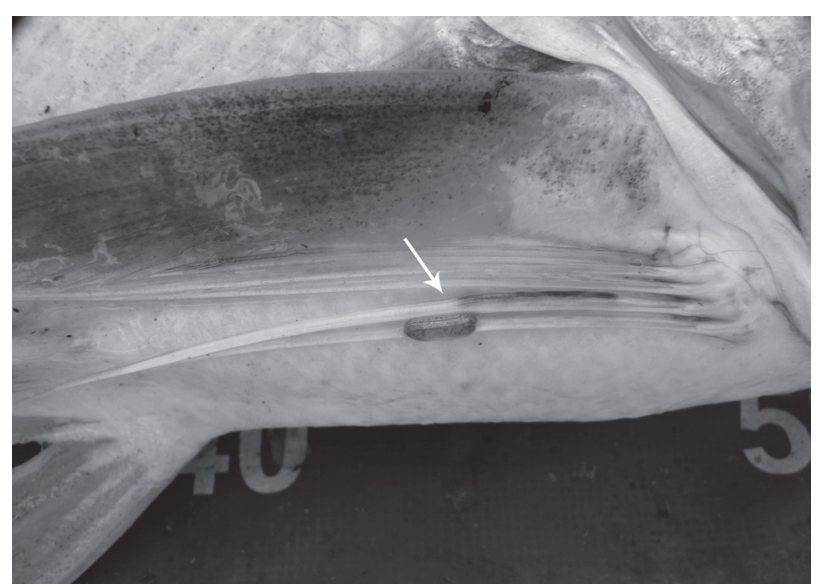

Fig. 9. Sensory fin of Polydactylus macrochir infected with two females of Philometra macrochiri (see arrow).

form and perciform fishes in the North Pacific (Margolis and Moravec 1987, Moravec 2006), and Clavinemoides annulatus Moravec, Khosheghbal et Pazooki, 2013, a parasite of the caudal fin of Otolithes ruber (Bloch et Schneder) (Sciaenidae) in the Persian Gulf off Iran (Moravec et al. 2013). However, species of both Clavinema Yamaguti, 1935 and Clavinemoides Moravec, Khosheghbal et Pazooki, 2013 are characterized by a triangular oral aperture.

The morphology of the new species, particularly the presence of a large anterior oesophageal bulb and 16 very small cephalic papillae, is also similar to Philometroides trichiuri Moravec, Walter et Yuniar, 2012 from the dorsal fin of Trichiurus lepturus and Lepturacanthus savala (Cuvier) (both Trichiuridae) in the Indian Ocean off the southern coast of Java, Indonesia (Moravec et al. 2012). However, $P$. trichiuri differs mainly in having distinct cuticular ornamentations (bosses and transverse mounds).

Of the philometrid species hitherto reported from fishes of the family Polynemidae (see above), the new species can be easily distinguished from Philometra beninensis by the absence of eight conspicuously large fleshy cephalic papillae, from Philometra polynemii by the absence of large caudal projections and from Philometroides eleutheronemae by the absence of cuticular bosses and the presence of a well developed anterior oesophageal bulb.

\section{Philometra zabidii sp. n.}

Figs. 10, 11

Female (one subgravid specimen, holotype): Body of fixed specimen whitish, filiform, with rounded ends. Cuticle smooth. Body length $114 \mathrm{~mm}$, maximum width 816, maximum width/body length ratio $1: 140$. Width of cephalic end 272. Cephalic papillae small, indistinct when viewed laterally (Fig. 10A,D). Oral aperture oval, surrounded by four pairs of submedian cephalic papillae of external circle and six single papillae (two lateral and four submedian) of internal circle (Figs. 10C, 11A). All papillae fairly large as compared to those in other gonadinfecting congeners; all external papillae oval shaped in apical view; all internal papillae very close to oral aperture. Amphids slightly outlined.

Entire oesophagus 789 long, comprising $0.7 \%$ of body length; anterior inflation weakly developed, 75 long, 108 wide; maximum width of oesophagus including gland 122. Oesophageal gland opening into oesophagus just posterior to nerve ring, with large cell nucleus in middle (Fig. 10A). Nerve ring and oesophageal nucleus 218 and 503, respectively, from anterior extremity. Small ventriculus 41 long and 82 wide. Oesophagus opening into intestine through distinct valve (Fig. 10A). Intestine darkbrown, narrow at anterior end; its posterior end markedly narrow, attached by ligament ventrally to body wall near caudal end (Fig. 10B); length of ligament 435.

Vulva and anus atrophied. Ovaries long, reflected, situated near body ends (Fig. 10A,B). Uterus occupying most space of body, filled with numerous eggs. Posterior end rounded, 231 wide, with two distinct lateral papilla-like caudal projections 6 high (Figs. 10B,E, 11B).

\section{Male: Unknown.}

Type host: Ninespine batfish, Zabidius novemaculeatus (McCulloch) (Ephippidae, Perciformes).

Site of infection: Ovary.

Type locality: Adelaide River, near Darwin, Australia (collected 13 October 2012 by K.S. Hutson).

Prevalence and intensity: 20\% (1 fish infected/5 fish examined from Adelaide River; mean intensity 2 nematodes per fish). Not present in 11 fish from Darwin Harbour or 3 fish from Bynoe Harbour. Overall prevalence $=1 / 19$ fish $(5 \%)$; 1 specimen.

Deposition of type specimen: Holotype (SEM stub) in the Helminthological Collection of the Institute of Parasitology, Biology Centre of the Academy of Sciences of the Czech Republic, České Budějovice (Cat. No. N - 1018).

Etymology: The specific name of this nematode relates to the genitive form of the generic name of the host.

Remarks. At present, 37 gonad-infecting species of Philometra are known to parasitize marine and brackishwater fishes (Moravec and Ali 2013). Gravid and subgravid females of all of them possess either no or poorly developed, hardly visible papilla-like caudal projections. In contrast, the caudal projections of the only available specimen from $Z$. novemaculeatus are marked, $6 \mu \mathrm{m}$ high (Figs. 10B,E, 11B). Cephalic papillae are also larger than in other gonad-infecting congeners and their distribution is somewhat different (all papillae of the internal circle are very close to the oral aperture), whereas in other species each submedian pair of the external circle is generally composed of one circular and one elongate papilla, all papillae seem to be oval in apical view in the new species (Figs. 10C, 11A). In contrast to most gonad-infecting congeneric species, the anterior oesophageal inflation is poorly developed. There are distinct body length differences between the new species and some other congeners. It can be expected that more interspecific differences will be 

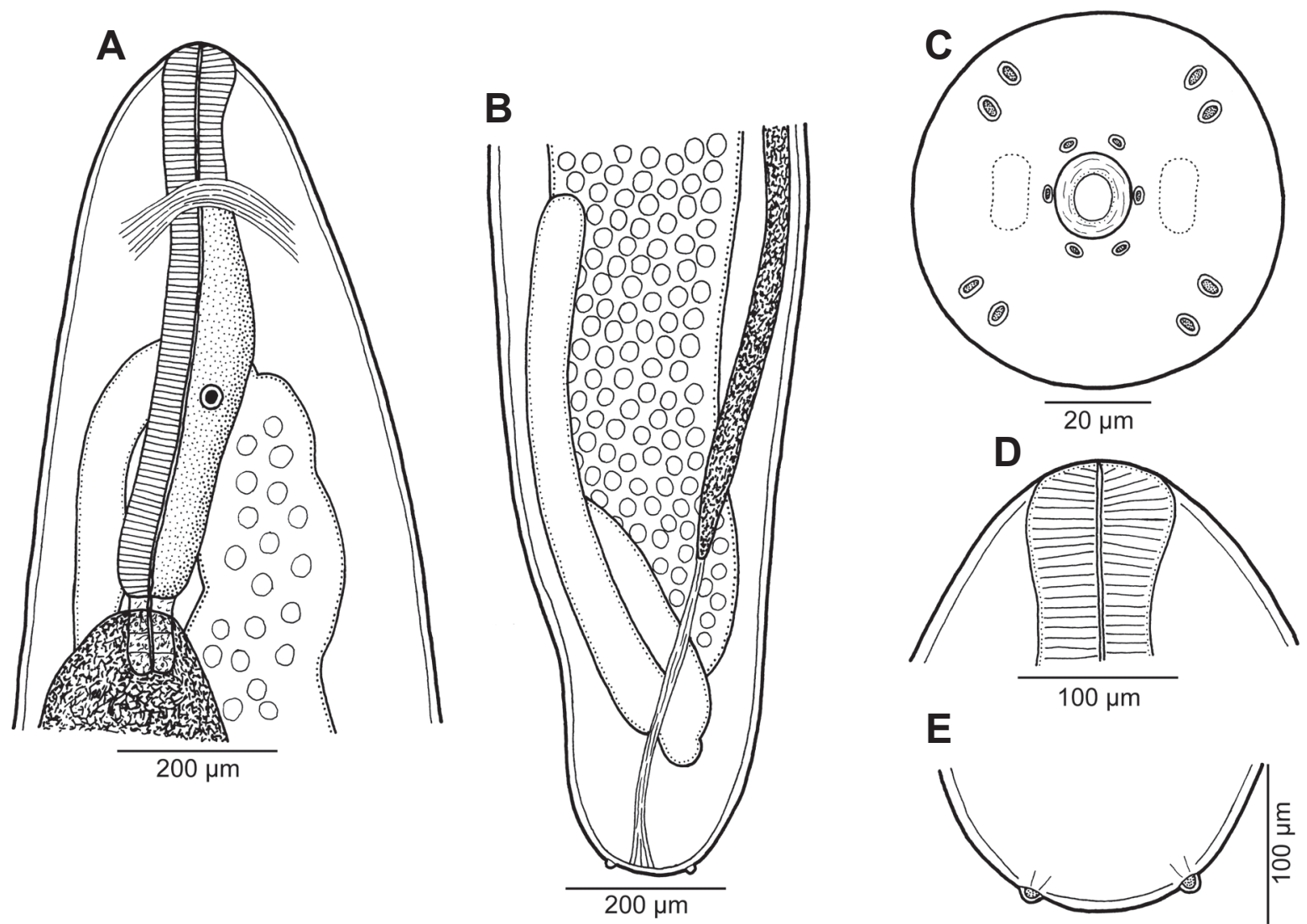

Fig. 10. Philometra zabidii sp. n. from ovary of Zabidius novemaculeatus, subgravid female. A - anterior end of body, lateral view; B - posterior end, dorsoventral view; C, D - cephalic end, apical and lateral views; $\mathbf{E}$ - tail tip, dorsoventral view.


Fig. 11. Philometra zabidii sp. n. from ovary of Zabidius novemaculeatus, scanning electron micrographs of subgravid female. A - cephalic end, apical view; B - posterior end of body, apical view (arrows indicate caudal projections). Abbreviations: a - submedian pair of cephalic papillae of external circle; $b$ - submedian cephalic papilla of internal circle; $c$ - lateral cephalic papilla of internal circle.

found in males of this species when they are discovered. Taking into account that philometrids generally exhibit a narrow degree of host specificity, it is also important that P. zabidii sp. $\mathrm{n}$. is the first philometrid species recorded from a representative of the fish family Ephippidae.

\section{Philometra sp. 1}

Fig. 12

Female (one subgravid specimen): Body of fixed specimen dark-brown, with rounded ends. Posterior part of body narrower than anterior part; maximum width in region posterior to oesophagus. Cuticle smooth. Body 
length $29.44 \mathrm{~mm}$, maximum width 435, maximum width/ body length ratio $1: 68$. Width of cephalic end 150 . Cephalic papillae small, indistinct when viewed laterally (Fig. 12A,B). Oesophagus including anterior bulbous inflation $1.02 \mathrm{~mm}$ long, comprising 3\% of body length; anterior inflation 109 long and 109 wide; maximum width of posterior part of oesophagus including gland 95 .

Oesophageal gland opening into oesophagus just posterior to nerve ring (Fig. 12A). Nerve ring 204 from anterior extremity; oesophageal nucleus not located. Small ventriculus 41 long and 82 wide. Oesophagus opening into intestine through distinct valve. Intestine narrow at anterior end; its posterior end attached by ligament ventrally to body wall near caudal end (Fig. 12C). Uterus filled with numerous spherical eggs occupying most space of body, reaching anteriorly to nerve ring and posteriorly nearly to body extremity (Fig. 12A,C). Posterior end rounded, 204 wide, caudal projections not visible (Fig. 12C).

Host: Spanish flag snapper, Lutjanus carponotatus (Richardson) (Lutjanidae, Perciformes).

Site of infection: Ovary.

Locality: Inner Darwin Harbour, near Darwin, Australia (collected 14 October 2012 by K.S. Hutson).

Prevalence and intensity: 2\% (1 fish infected/52 fish examined from Darwin Harbour; 1 nematode). Not present in 17 fish from outer Darwin Harbour or 17 fish from Bynoe Harbour or 9 fish from Adelaide River. Overall prevalence $=$ 1/78 fish (1\%); 1 specimen.

Deposition of specimen: Helminthological Collection of the Institute of Parasitology, Biology Centre of the Academy of Sciences of the Czech Republic, České Budějovice (Cat. No. N-1020).

Remarks. Since only a single, rather small subgravid female specimen is available, it cannot be identified to species. Because its morphology and measurements are very similar to those of the subgravid female of Philometra brevicollis Moravec et Justine, 2011, a gonad-infecting species described from Lutjanus vitta (Quoy et Gaimard) off New Caledonia (Moravec and Justine 2011), it may belong to the same species. However, Moravec and Justine (2011) also recorded from the ovary of $L$. vitta off New Caledonia the males of another Philometra species, $P$. mira Moravec et Justine, 2011, morphologically different from $P$. brevicollis. Therefore, both males and gravid females are necessary for species identification of this gonad-infecting philometrid from L. carponotatus in Australian waters.

The present material also contains two body fragments of the posterior body part of a subgravid female of Philometra (total length of fragments $40 \mathrm{~mm}$ ) from the gills of the golden snapper Lutjanus johnii (Bloch) collected in the same locality on 20 November 2012. Even though the anterior end of this specimen is lacking, the morphology and measurements indicate that it may be conspecific with that from L. carponotatus. It is highly probable that the nematode was found in the host's gills only via contamination during the fish dissection.
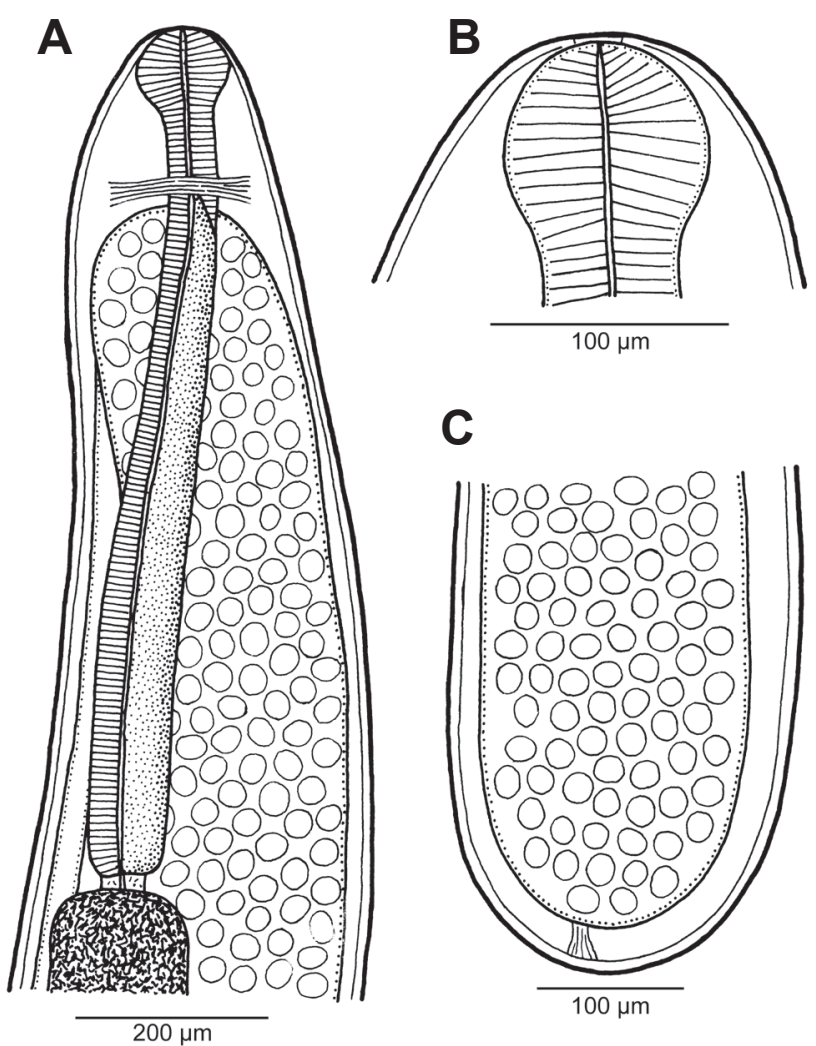

Fig. 12. Philometra sp. 1 from gonad of Lutjanus carponotatus, subgravid female. A - anterior end of body; B - cephalic end; $\mathbf{C}$ - posterior end (all lateral views).

\section{Philometra sp. 2}

Fig. 13

Female (body fragments of one subgravid specimen): Body of fixed specimen brownish, filiform, with rounded ends. Cuticle smooth. Total length of body fragments $88 \mathrm{~mm}$, maximum width $1.29 \mathrm{~mm}$. Width of cephalic end 326. Cephalic papillae small, indistinct when viewed laterally (Fig. 13A,B). Oesophagus including anterior bulbous inflation $1.71 \mathrm{~mm}$ long; anterior bulb well developed, 122 long and 163 wide; maximum width of posterior part of oesophagus including gland 150 .

Oesophageal gland opening into oesophagus just posterior to nerve ring (Fig. 13A). Nerve ring 286 from anterior extremity; oesophageal nucleus located at about $2 / 3$ of gland length. Oesophagus opening into intestine through distinct valve (Fig. 13A). Intestine dark-brown, relatively narrow at anterior end (Fig. 13A), ending blindly; intestinal ligament indistinct.

Uterus filled with numerous spherical eggs occupying most space of body, reaching anteriorly to nerve ring and posteriorly nearly to body extremity (Fig. 13A,D). Posterior end rounded, 449 wide, caudal projections not visible (Fig. 13D).

Host: Silver grunt, Pomadasys argenteus (Forsskål) (Haemulidae, Perciformes).

Site of infection: Ovary.

Locality: Darwin Harbour, near Darwin, Australia (collected 

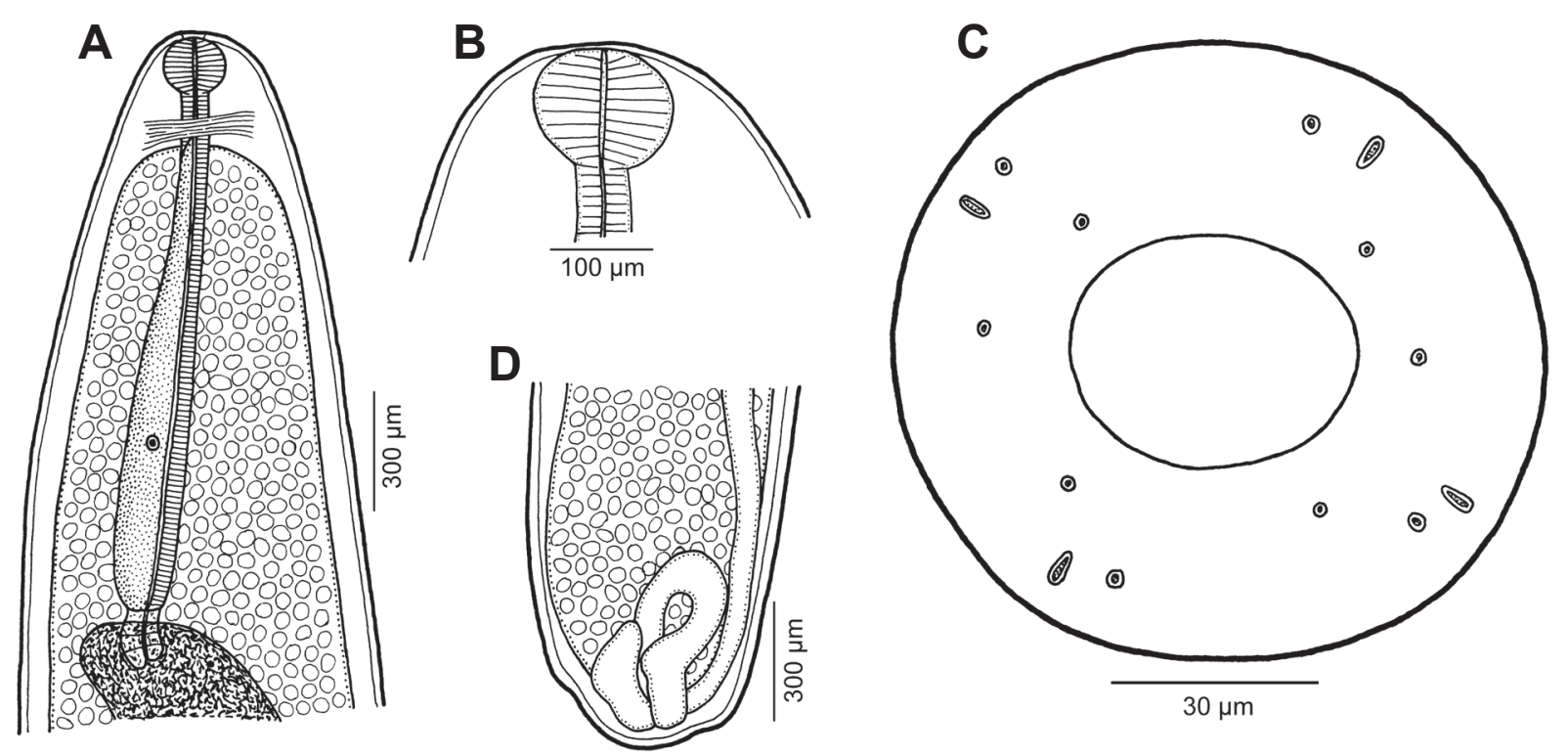

Fig. 13. Philometra sp. 2 from gonad of Pomadasys argenteus, subgravid female. A - anterior end of body; B, C - cephalic end, lateral and apical views, $\mathbf{D}$ - posterior end, lateral view.

13 October 2012 by K.S. Hutson and 20 November 2012 by B.K. Diggles).

Prevalence and intensity: $8 \%$ (4 fish infected $/ 52$ fish examined from Darwin Harbour; mean intensity 2.3 nematodes per fish, range 1-3). Not present in 19 fish from Bynoe Harbour or 26 fish from Adelaide River. Overall prevalence $=4 / 98$ fish (4\%); mean intensity 2.3 specimens.

Deposition of specimen: Helminthological Collection of the Institute of Parasitology, Biology Centre of the Academy of Sciences of the Czech Republic, České Budějovice (Cat. No. N-1021).

Remarks. The morphology of this specimen is more or less typical of gonad-infecting Philometra spp. It may belong to an undescribed species, but having no conspecific males or gravid females, we refrain from the erection of a new species based on this material.

Philometroides eleutheronemae Moravec et Manoharan, 2013

Fig. 14

Female (four subgravid specimens): Body of fixed specimens brownish, filiform, 19.9-50.5 mm long and 163-476 in maximum width; maximum width/length ratio of body 1 : 98-141. Width of cephalic end 122-272, that of caudal end 109-177. Entire body with sparsely distributed small cuticular bosses 3-6 high on surface (Fig. 14C,D); bosses absent from oesophageal region and rarely scattered on rest of body; bosses completely absent in specimens shorter than $24 \mathrm{~mm}$. Anterior end of body rounded, bearing two small lateral elevated protuberances (Fig. 14B). Cephalic papillae small, indistinct in lateral view.

Oesophagus muscular, with moderately developed elongate anterior inflation, 571-952 long, comprising $1.9-2.5 \%$ of body length (Fig. 14A); maximum width of posterior portion of oesophagus 68-95. Anterior oesophageal inflation 69-122 long and 75-122 wide. Oesophageal gland moderately developed, starting at level of nerve ring and extending posteriorly to end of oesophagus (Fig. 14A); nucleus of oesophageal gland 360-612 from anterior end of body. Small ventriculus 12-27 long and 39-45 wide, opening into intestine through valve (Fig. 14A). Nerve ring 109-218 from anterior extremity. Intestine dark-brown, straight; posterior end of intestine atrophied, forming ligament 190-279 long attached to posterior extremity (Fig. 14D).

Uterus, containing numerous eggs, extending anteriorly to nerve ring and posteriorly nearly to body extremity (Fig. 14A,D). Posterior end of body rounded, provided with pair of small but distinct lateral papilla-like caudal projections 3 high (Fig. 14D).

\section{Male: Unknown.}

Host: Fourfinger threadfin, Eleutheronema tetradactylum (Shaw) (Polynemidae, Perciformes).

Site of infection: Ovary.

Locality: Darwin Harbour, near Darwin, Australia (collected 15 September 2012 by K.S. Hutson).

Prevalence and intensity: 18\% (3 fish infected/20 fish examined from Darwin Harbour; mean intensity 4.3 nematodes per fish, range 1-10). Not present in 7 fish from Bynoe Harbour or 3 fish from Adelaide River. Overall prevalence $=3 / 30$ fish (10\%); mean intensity 4.3 .

Deposition of voucher specimens: Helminthological Collection of the Institute of Parasitology, Biology Centre, Academy of Sciences of the Czech Republic, in České Budějovice (Cat. No. N-1004).

Remarks. The morphology and measurements of the present specimens correspond to those of Philometroides 

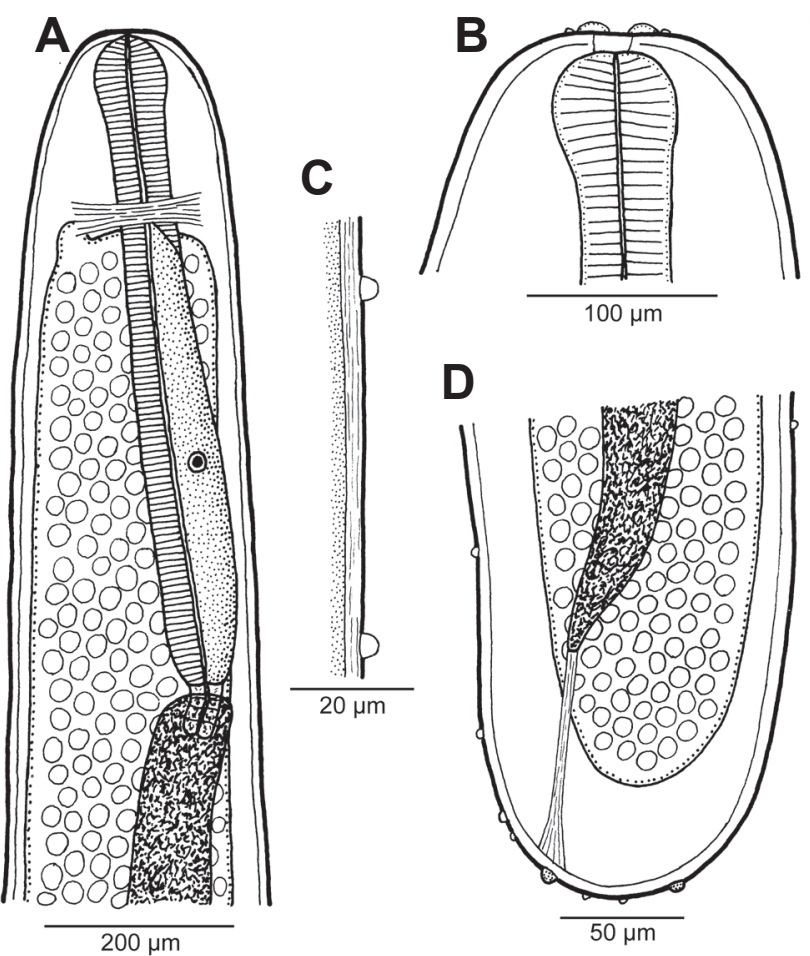

Fig. 14. Philometroides eleutheronemae Moravec et Manoharan, 2013 from ovary of Eleutheronema tetradactylum, subgravid female. A - anterior end; B - cephalic end; $\mathbf{C}$ - body cuticle with bosses; $\mathbf{D}$ - posterior end (all lateral views).

eleutheronemae Moravec et Manoharan, 2013, a gonad infecting philometrid recently described from the same host species (E. tetradactylum) in the Bay of Bengal, off India (Moravec and Manoharan 2013). This is the first record of $P$. eleutheronemae from Australian waters. The males of this species have not yet been described.

Spirophilometra endangae Dewi et Palm, 2013

Figs. 15, 16

Female (five gravid specimens; measurements of four subgravid specimens in parentheses): Body of fixed specimens red-brown, cylindrical, markedly tapering at both ends, 21.1-42.2 (8.4-16.0) mm long, maximum width 938-1197 (340-775). Maximum width/length ratio of body $1: 21-35(1: 25-29)$. Cuticle of entire body densely covered with minute spines, mostly not arranged in transverse rows (Fig. 16B-H). Cephalic papillae small, not visible when viewed laterally (Fig. 15A,D). Oral aperture small, oval to nearly circular, surrounded by four pairs of submedian cephalic papillae of external circle and six (two lateral and four submedian) single papillae of internal circle; each external pair formed by one smaller, almost circular papilla and one larger elongate papilla (Figs. 15C, 16B). Lateral amphids slightly outlined.

Small oesophageal teeth (lobes) present in one gravid and three subgravid specimens (Figs. 15B,H, 16C,F); teeth 2 (5-6) high. Anterior end of oesophagus swollen to form well-developed bulb 84-109 (54-75) long and 75-99 (54-72) wide. Long posterior portion of oesophagus provided with well-developed, broad oesophageal gland extending anteriorly to short distance posterior to level of nerve ring; oesophageal gland contains large cell nucleus located somewhat posterior to its middle, at 734-802 (503-517) from anterior extremity (Fig. 15A). Overall length of oesophagus including anterior bulb 933-1142 (707-1129) mm, representing 3-5 (5-9) \% of body length; maximum width of its posterior part including oesophageal gland 122-150 (63-82).

Small ventriculus, 27-33 (14-41) long and 54-68 (45-68) wide, opening into intestine through valve. Nerve ring 177-286 (177-190) from anterior end of body (Fig. 15A). Intestine light-brown, narrow, its posterior end atrophied, forming ligament 105-240 (99-313) long attached subventrally to body wall near posterior extremity. Posterior end of body narrowed, rounded, bearing two distinct lateral papilla-like projections (Figs. 15G,J, $16 \mathrm{D}, \mathrm{E})$. Ovaries relatively short, narrow, reflected (Fig. 15B,F). Uterus occupying major part of body, extending anteriorly to some distance posterior to nerve ring. Uterus filled with numerous larvae 381-429 long and 15-18 (-) in maximum width $(\mathrm{n}=5)$ (Fig. 15F); length of oesophagus $108-123$ (28-31\% of body length), that of slender, sharply pointed tail $75-81$ (19-20\% of body length).

Male: Unknown.

Host: Orange-spotted grouper, Epinephelus coioides (Hamilton) (Serranidae, Perciformes).

Site of infection: Pectoral fins.

Localities: Darwin Harbour, Bynoe Harbor and Adelaide River, near Darwin, Australia (collected 28 August and 7 October 2012 by B.K. Diggles).

Prevalence and intensity: 60\% (9 fish infected/15 fish examined from Adelaide river; mean intensity 6.7 nematodes per fish, range 1-13). Also present in 10 fish from Bynoe Harbour from 21 fish examined (prevalence 48\%, mean intensity 1.6 nematodes per fish, range 1-3), 14 fish from Darwin Harbour from 38 fish examined (prevalence 37\%, mean intensity 1.7 nematodes per fish, range $1-3$ ). Overall prevalence $=33 / 74$ fish $(45 \%)$; mean intensity $=3$, range $1-13$.

Deposition of voucher specimens: Helminthological Collection of the Institute of Parasitology, Biology Centre, Academy of Sciences of the Czech Republic, in České Budějovice (Cat. No. N-1010).

Remarks. The morphology of specimens of the present material is in agreement with the description of S. endangae Dewi et Palm, 2013, a philometrid recently described from fins of Epinephelus coioides in the South Bali Sea, Indonesia (Dewi and Palm 2013). Since also the host species and the site of infection in the host are identical, there is no doubt that the present specimens belong to this species. Dewi and Palm (2013) reported the body length of $S$. endangae gravid females to be $10.5-21.6 \mathrm{~mm}$, whereas those of the present material were mostly longer 



Fig. 15. Spirophilometra endangae Dewi et Palm, 2013 from pectoral fin of Epinephelus coioides, gravid and subgravid female. $\mathbf{A}$ - anterior end of gravid specimen, lateral view; $\mathbf{B}$ - anterior end of smallest subgravid specimen, lateral view; $\mathbf{C}, \mathbf{D}$ - cephalic and of gravid specimen, apical and lateral views; E, F - anterior and posterior end of smallest subgravid specimen, lateral views; $\mathbf{G}$ - larva from uterus, lateral view; H, I - caudal end of two different gravid specimens, lateral views; $\mathbf{J}$ - detail of cuticle with spines, lateral view.

(21.1-42.2 mm), which extends considerably the biometrical variability of this species. Moreover, it is reported here for the first time that well-developed oesophageal teeth (lobes) (Figs. 14B,H, 15C,F) may be present in some gravid and subgravid female specimens of $S$. endangae. According to Dewi and Palm (2013), Philometra sp. reported by Palm and Rückert (2009) from E. coioides in Segara Anakan lagoon, Indonesia, belonged in fact 

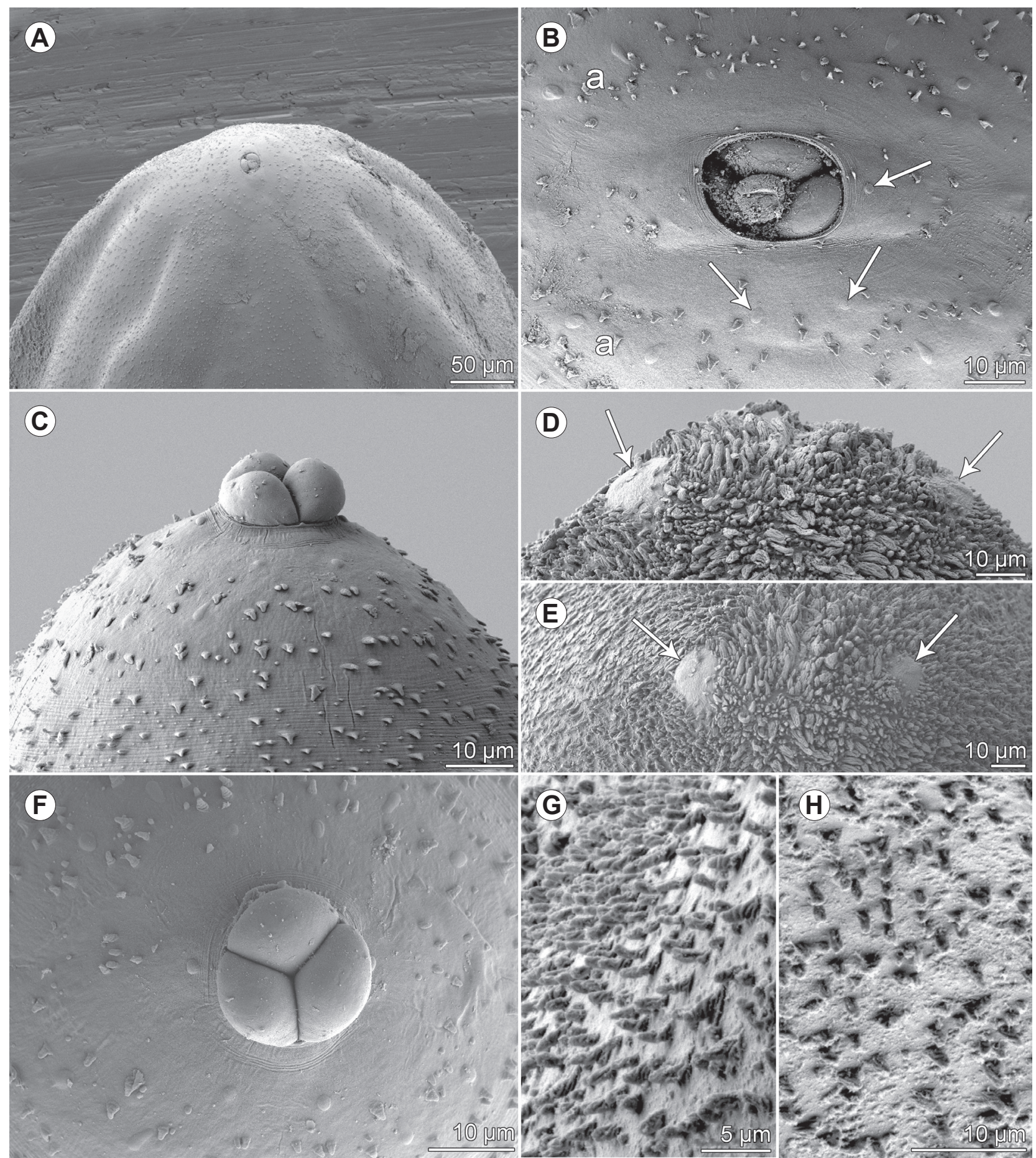

Fig. 16. Spirophilometra endangae Dewi et Palm, 2013 from pectoral fin of Epinephelus coioides, scanning electron micrographs of gravid (A, B, D, E, G, H) and subgravid (C, F) females. A - anterior end of body, sublateral view; B - cephalic end, apical view (arrows indicate lateral and submedian papillae of internal circle); C, F - cephalic end of specimen with distinctly extruding anterior oesophageal lobes (teeth), ventral and apical views; D, E - posterior end of body, lateral and apical views (arrows indicate caudal projections); G, $\mathbf{H}$ - cuticular spines. Abbreviation: a - submedian pair of cephalic papillae of external circle.

to $S$. andangae. The present finding is the first record of S. endangae from Australian waters.

The only other congeneric species studied by SEM is S. pacifica Moravec, Santana-Piñeros, González-Solís et Torres-Huerta, 2007, a parasite of the mouth cavity of
Centropomus robalito Jordan et Gilbert (Centropomidae) off the Pacific coast of Mexico (Moravec et al. 2007). In addition to the features of this species distinguishing it from S. endangae mentioned by Dewi and Palm (2013), there is a substantial difference between these two species 
in the absence/presence of cuticular spines in the cephalic region. Whereas the cephalic extremity of $S$. pacifica is smooth and the cuticular spination starts at short distance posterior to cephalic papillae, the cuticular spines in $S$. endangae extend anteriorly up to the oral aperture, individual spines being present among cephalic papillae (Fig. 15B).

Acknowledgements. For their help with field collections we thank Will Macbeth and Lachlan Barnes. Other field staff from Cardno Environmental Services and Quentin Allsop, Wayne Baldwin, Chris Errity and other field staff from NT Fisheries assisted with field collections. Kate S. Hutson aided with fish necropsies and collected representative specimens for morphological studies. This project was undertaken by DigsFish Services as part of environmental monitoring for the Ichthys Gas Field Development Project. Authors' thanks are also due to the staff of the Laboratory of Electron Microscopy, Institute of Parasitology, Biology Centre of the AS CR, České Budějovice for their technical assistance, and to Blanka Škoríková of the same Institute for help with illustrations. This study was partly supported by the Czech Science Foundation (grant No. P505/12/G112) and the Institute of Parasitology, BC AS CR (institutional support RVO: 60077344).

\section{REFERENCES}

Dewi K., Palm H.W. 2013: Two new species of philometrid nematodes (Nematoda: Philometridae) in Epinephelus coioides (Hamilton, 1922) from the South Bali Sea, Indonesia. Zootaxa 3609: 49-59.

Froese R., Pauly D. (Eds.) 2013: FishBase. World Wide Web electronic publication, www.fishbase.org, 06/2013.

Hesp S.A., Hobbs R.P., Ротter I.C. 2002: Infection of the gonads of Glaucosoma hebraicum by the nematode Philometra lateolabracis: occurrence and host response. J. Fish Biol. 60: 663-673.

Ivashin V.M., Sobolev A.A., Khromova L.A. 1971: [Camallanata of Animals and Man and the Diseases Caused by Them. Osnovy Nematodologii 22.] Nauka, Moscow, 388 pp. (In Russian.)

Johnston T.H., Mawson P. 1940: Some nematodes parasitic in Australian freshwater fish. Trans. Roy. Soc. S. Australia 64: 340-352.

Margolis L., MoraVec F. 1987: A record of Clavinema mariae (Layman, 1930) (Nematoda: Philometridae) from a North American freshwater fish, with notes on the systematic status of Philometra americana Kuitunen-Ekbaum, 1933. Folia Parasitol. 34: 31-36 + $1 \mathrm{Pl}$.

Moravec F. 2006: Dracunculoid and Anguillicoloid Nematodes Parasitic in Vertebrates. Academia, Prague, $634 \mathrm{pp}$.

Moravec F. 2008: Systematic status of Philometra jordanoi (López-Neyra, 1951) and some other congeneric species previously identified as Philometra lateolabracis (Yamaguti, 1935) (Nematoda: Philometridae). Folia Parasitol. 55: 159-160.

Moravec F., Ali A.H. 2005: Two new species of Philometra (Nematoda: Philometridae) from needlefishes (Belonidae) in Iraq, with a key to Philometra spp. parasitic in the host's subcutaneous tissue, fins and musculature. Folia Parasitol. 52: 267-273.

Moravec F., Ali A.H. 2013: Philometra johnii sp. nov. (Nematoda, Philometridae), a new gonad-infecting philometrid from the sin croaker Johnius dussumieri (Cuvier) (Pisces, Sciaenidae) from marine waters of Iraq. Acta Parasitol. 58: 263-268.

Moravec F., De Buron I. 2013: A synthesis of our current knowledge of philometrid nematodes, a group of increasingly important fish parasites. Folia Parasitol. 60: 81-101.

Moravec F., Justine J.-L. 2008: Some philometrid nematodes (Philometridae), including four new species of Philometra,

Received 14 June 2013 from marine fishes off New Caledonia. Acta Parasitol. 53: 369-381.

Moravec F., Justine J.-L. 2009: New data on dracunculoid nematodes from fishes off New Caledonia, including four new species of Philometra (Philometridae) and Ichthyofilaria (Guyanemidae). Folia Parasitol. 56: 129-142.

Moravec F., Justine J.-L. 2011: Two new gonad-infecting Philometra species (Nematoda: Philometridae) from the marine fish Lutjanus vitta (Perciformes: Lutjanidae) off New Caledonia. Folia Parasitol. 58: 302-310.

Moravec, Khosheghbal M., Pazooki J. 2013: Two philometrids (Nematoda: Philometridae) infecting the tigertooth croaker Otolithes ruber (Teleostei: Sciaenidae) off Iran, including erection of a new genus. Syst. Parasitol., 86: 33-41.

Moravec F., Manoharan J. 2013: Gonad-infecting philometrids (Nematoda: Philometridae) including four new species from marine fishes off the eastern coast of India. Folia Parasitol. 60: $105-122$.

Moravec F., Rohde K. 1992: Three species of nematodes of the superfamily Dracunculoidea from Australian fishes. Acta Soc. Zool. Bohemoslov. 56: 187-195.

Moravec F., Santana-Piñeros A.M., González-Solís D., Torres-Huerta A.M. 2007: A new species of Spirophilometra (Nematoda: Philometridae) from the yellowfin snook Centropomus robalito (Osteichthyes) in southern Mexico. Folia Parasitol. 54: 215-219.

Moravec F., Walter T., Yuniar A.T. 2012: Five new species of philometrid nematodes (Philometridae) from marine fishes off Java, Indonesia. Folia Parasitol. 59: 115-130.

PALM H.W., RÜCKERT S. 2009: A new approach to visualize ecosystem health by using parasites. Parasitol. Res. 105: 539-553.

Parukhin A.M. 1976: [Parasitic Worms of Commercial Fishes of the Southern Seas.] Naukova Dumka, Kiev, 183 pp. (In Russian.)

Quiazon K.M.A, Yoshinaga T., Ogawa K. 2008: Taxonomical study into two new species of Philometra (Nematoda: Philometridae) previously identified as Philometra lateolabracis (Yamaguti, 1935). Folia Parasitol. 55: 29-41.

Rasheed S. 1963: A revision of the genus Philometra Costa, 1845. J. Helminthol. 37: 89-130.

Soota T.D. 1983: Studies on Nematode Parasites of Indian Vertebrates. I. Fishes. Rec. Zool Surv. Ind. Occ. Pap. No. 54. Zoological Survey of India, Calcutta, $352 \mathrm{pp}$. 